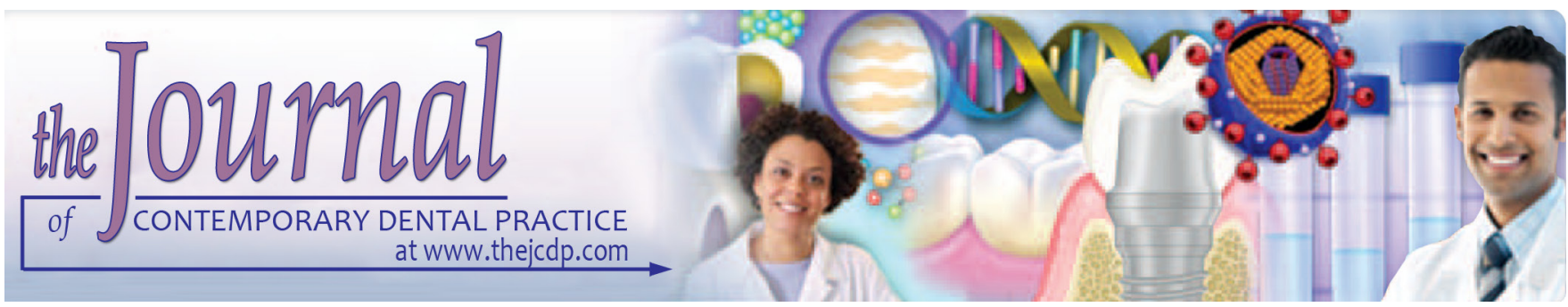

\title{
Evaluation of the Apical Seal of Mineral Trioxide Aggregate in the Absence and Presence of Smear Layer
}

\author{
${ }^{1}$ Enass Shamsy, ${ }^{2}$ Mohammad Z Nassani, ${ }^{3}$ Adnan A Habib, ${ }^{4}$ Mazen Doumani
}

\begin{abstract}
Aim: The aim of this study was to in vitro evaluate the apical sealability of mineral trioxide aggregate (MTA) when used as an orthograde root filling material, and to evaluate whether smear layer removal has any influence on the apical seal of this material.
\end{abstract}

Materials and methods: Forty single-rooted human mandibular premolars were selected in this in vitro study. The selected teeth were randomly divided into two equal groups ( $n=20$ ) based on the irrigation type. Group 1 was irrigated using distilled water to keep the smear layer intact, and group 2 was irrigated using $\mathrm{NaOCl} 5.25 \%$ and ethylenediaminetetraacetic acid (EDTA) 17\% to remove the smear layer. All teeth were instrumented using a step-back technique and obturated using white MTA. Microleakage of $0.2 \%$ rhodamine B solution at the tooth-material interface was evaluated to assess the apical seal of MTA. The data were analyzed statistically using Mann-Whitney test U-test $(p=0.05)$.

Results: When the smear layer was present, MTA revealed less leakage compared to the group of MTA without smear layer with statistically significant difference $(p<0.05)$.

Conclusion: The apical seal produced by MTA when smear layer is left intact was better than the apical seal of MTA when smear layer is removed.It can be stated that MTA is a promising root canal filling material with good sealing ability in the presence of a smear layer.

${ }^{1}$ Dental Health Care Department, Inaya Medical College, Riyadh, Kingdom of Saudi Arabia

${ }^{2,4}$ Department of Prosthetic Dental Sciences, AlFarabi College for Dentistry and Nursing, Riyadh, Kingdom of Saudi Arabia

${ }^{3}$ Department of Restorative Dental Sciences, Faculty of Pharmacy and Dentistry, Buraydah Colleges, Al Qassim, Kingdom of Saudi Arabia

Corresponding Author: Adnan A Habib, Department of Restorative Dental Sciences, Faculty of Pharmacy and Dentistry, Buraydah Colleges, Al Qassim, Kingdom of Saudi Arabia, Phone: 00966-12273151, e-mail: adnanhabib71@ hotmail.com
Clinical significance: Using white MTA material for the obturation of root canals is a useful procedure. It could be done without complexity in irrigation during root canal treatment and cause no discoloration to the teeth.

Keywords: Microleakage, Mineral trioxide aggregate, Obturation, Smear layer.

How to cite this article: Shamsy E, Nassani MZ, Habib AA, Doumani M. Evaluation of the Apical Seal of Mineral Trioxide Aggregate in the Absence and Presence of Smear Layer. J Contemp Dent Pract 2019;20(3):298-303.

Source of support: Nil

Conflict of interest: None

\section{INTRODUCTION}

The objectives of endodontic treatment are to clean and shape the root canal system and to seal this system with a permanent three dimensional (3D) filling that does not allow leakage. ${ }^{1}$ The criteria for an ideal root canal obturation material include excellent adaption to the walls of the preparation, nontoxicity, well tolerated by the periapical tissues, promoting healing, noncorrosive, dimensionally stable, radiopaque, nonabsorbable, and not be affected by the presence of moisture or blood. ${ }^{2}$ In addition, the obturation material should be sterilizable, nonstaining, and able to be placed and removed easily from the root canal system. However, the improvement of endodontic materials and treatment concepts has led to a considerable reexamination and reassessment of the aforementioned criteria. ${ }^{3}$ It might be contraindicated, for example, that the material used for obturation should be easily removed from the root canal system because ideal obturation requires a material that essentially provides a resistant and steady hermetic seal. ${ }^{3}$

Among the different obturation materials, guttapercha is still the dominant material for root canal obturation because of its advantages such as ease of use, handling properties, and biocompatibility. However, gutta-percha is characterized by inherent weakness 
which makes it not the ideal material for root canal obturation. The ideal root canal obturation material has not yet been established. ${ }^{3}$

Mineral trioxide aggregate (MTA) was first introduced as a root-end filling material in $1993 .^{4}$ The aggregate has special chemical and physical properties due to the hydrophilic particles (tricalcium silicate and tricalcium aluminate) in the composition of the powder of MTA in addition to the other fine trioxides (tricalcium oxide, silicate oxide, bismute oxide). This material set in the presence of moisture, and takes about 3-4 hours to set with a $\mathrm{pH}$ of $12.5 .^{5}$ The biocompatibility of MTA and its antibacterial properties, marginal adaptation, sealing properties, and its hydrophilic nature make this material distinctive and different from other available obturation materials. ${ }^{5}$ This material showed excellent characteristics when used as a root-end filling material, pulp capping, pulpotomy, apical barrier formation in teeth with open apices, repair of root perforations, and root canal filling. ${ }^{6}$

MTA is available in two types based on the color known as gray and white MTA. Scanning electron microscopy (SEM) and electron probe microanalysis characterized the differences between GMTA and WMTA and found that the major difference between GMTA and WMTA is in the concentrations of $\mathrm{Al}_{2} \mathrm{O}_{3}, \mathrm{MgO}$ and FeO.?

It has been suggested to use MTA as an obturating material for the entire root canal system or as root canal sealer due to its good sealing ability and its property of setting with the presence of moisture. ${ }^{8,9}$ When MTA is used as root canal sealer and is compacted against dentin a dentin MTA interfacial layer forms in the presence of phosphate. This adherent interstitial layer resembles hydroxylapatite in composition and structure. ${ }^{10}$

Instrumentation of the root canal, using either manual or rotary techniques, during endodontic treatment creates a smear layer and smear plugs. ${ }^{11-13}$

The smear layer consists of inorganic particles of calcified tissue and organic elements such as pulp tissue debris, odontoblastic processes, microorganisms, and blood cells in dentinal tubules. ${ }^{14}$ It is not clear yet whether the smear layer should be removed or not before obturating the root canal. If the smear layer is left intact, it might interfere with the adaptation of the obturation materials to the root canal wall. ${ }^{15}$ In addition, it prevents irrigants, medicaments and filling materials from penetrating the dentinal tubules, and the presence of this layer is considered to be the cause of leakage between root canal walls and the obturation material. ${ }^{14}$ On the other side, it could be assumed that the smear layer can play a role in the protection from bacteriological diffusion and penetration into the dentinal tubules. ${ }^{16}$

This study aimed to in vitro assess the apical sealability of MTA when used as an orthograde root filling material, and to evaluate whether smear layer removal has any influence on the apical seal of this material.

\section{MATERIALS AND METHODS}

Forty single-rooted human mandibular premolars were selected in this in vitro study. The teeth were matched anatomically based on visual examination of buccolingual and mesio-distal radiographs. The inclusion criteria for the teeth were as follows: teeth exhibited one canal, confirmed by X-ray, had mature apices, no cracks, the roots were free from resorption, caries, and restorations, and were not dilacerated. The teeth were extracted due to periodontal or orthodontic considerations.

The teeth were randomly divided into two equal groups $(n=20)$ based on the irrigation type during root canal preparation. Group 1 was irrigated using distilled water to keep the smear layer intact and group 2 was irrigated using $\mathrm{NaOCl} 5.25 \%$ and EDTA $17 \%$ to remove the smear layer.

\section{Teeth Preparation}

Any adherent soft tissues, bone fragments or calculus were removed via scaling and polishing. The dental crowns were sectioned at the cementoenamel junction with a high-speed diamond bur (Komet, Gebr. Brasseler $\mathrm{GmbH} \&$ Co. KG Germany) under continuous water spray to obtain access to the root canal. The canal lengths were visually established by placing a size $10 \mathrm{~K}$ file (Mani Inc., Tochigi-Ken, Japan) into each root canal until the tip of the file was visible at the tip of the apical foramen. The working length was established $1 \mathrm{~mm}$ short of the apex. The canal systems were instrumented to the working length with a size \#40 K file by using a step-back technique.

In group 1, canals were irrigated with $1 \mathrm{~mL}$ of distilled water after each instrument using Max-I-Probe irrigation probes size 30 gauge (Dentsply Rinn, York, PA, USA) and finally flushed with $5 \mathrm{~mL}$ of distilled water.

In group 2, canals were irrigated with $1 \mathrm{~mL}$ of $5.25 \% \mathrm{NaOCl}$ after each instrument using Max-I-Probe irrigation probes size 30 gauge then irrigated with $3 \mathrm{~mL}$ of $17 \%$ EDTA (MD Cleanser, META Biomed, South Korea) for 1 minute followed by $3 \mathrm{~mL}$ of $5.25 \% \mathrm{NaOCl}$ in order to neutralize EDTA action in the root canal and finally flushed with $5 \mathrm{~mL}$ of distilled water. Root canals were then dried using sterile paper points (Diadent Group International, South Korea)

\section{Obturation of the Root Canals}

Root canals were obturated using WMTA (ProRootMTA; Tulsa Dental, Tulsa, OK) Powder and liquid were mixed according to the manufacturer's instructions. 
The mixture was applied to the canal using an amalgam carrier and then condensed vertically using hand pluggers (Dentsply/Maillefer, Ballaigues, Switzerland). Then, a moist cotton pellet was placed on top of the MTA mixture to allow complete setting.

The length and density of the root canal obturation and the absence of voids were confirmed radiographically. The access opening of all groups was sealed with an intermediate restorative material (IRM) (Dentsply DeTrey $\mathrm{GmbH}$, Konstanz, Germany) and the teeth were kept in $100 \%$ humidity at $37^{\circ} \mathrm{C}$ for 7 days to allow the obturation materials to set.

\section{Dye Infiltration}

The teeth surfaces were coated with two layers of nail varnish leaving the apical foramen of the root exposed. To test the nail varnish sealability and the penetrability of the dye in the root canal, six additional teeth were used; three were obturated using gutta-percha points vertically condensed with zinc oxide-eugenol sealer and considered as a positive control group. In addition, three teeth were left without obturation as a negative control group. The negative control group was completely coated with two layers of nail varnish, including the apical foramen.

All teeth of the specimen and the two control groups were put into test-tubes containing $0.2 \%$ rhodamine $B$ solution (SIGMA-ALDRICH, Co, USA)and centrifuged at $3000 \mathrm{rpm}$ for 5 minutes.

Subsequently, the teeth were rinsed under running water and allowed to dry at room temperature for 24 hours. Then, the teeth were sectioned longitudinally in a buccolingual direction with a diamond disk $(22 \mathrm{~mm}$ in diameter and $0.3 \mathrm{~mm}$ in thickness) using a low-speed handpiece with water coolant.

Afterward, the sections were examined under a stereomicroscope (Scope SC-S100, Germany) with (x20)

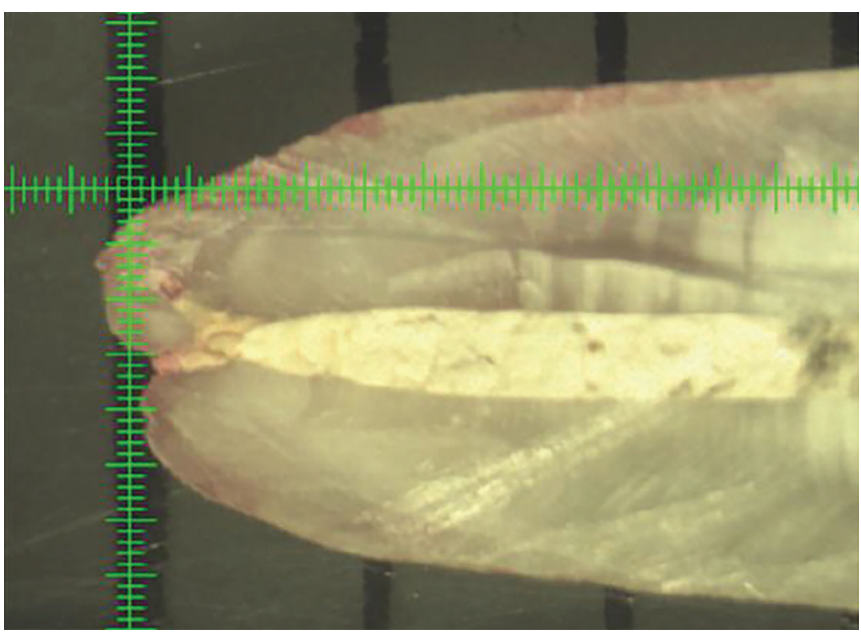

Fig. 1: A stereomicroscope image $(x 20)$ of the sample from group 1 (infiltration loss) magnification for evaluation of linear dye penetration at the tooth-material interface (Figs 1 and 2).

\section{Evaluation of Apical Leakage}

In this in vitro study Escobar et al.'s ${ }^{17}$ criteria were used to evaluate the infiltration proportions:

- 0 : Infiltration loss (dye penetration $0 \leq 1.5 \mathrm{~mm}$ ).

- 1: Simple infiltration (dye penetration 1.5-3 mm).

- 2: Medium infiltration (dye penetration $>3 \mathrm{~mm}$ ).

The data were analyzed with descriptive statistical methods using Mann-Whitney U-test $(p=0.05)$ using statistical package for social sciences (SPSS version 13.0, SPSS, Chicago, IL, USA). The level of significance was set at 0.05 .

\section{RESULTS}

Both groups demonstrated dye leakage. The scores for apical dye penetration evaluation by Escobar et al. criteria showed that group 2 (without smear layer) had a higher frequency of medium infiltration $(\mathrm{N}=17)$ and lower frequency of infiltration loss $(\mathrm{N}=0)$. The scores for apical dye penetration evaluation by Escobar et al. criteria are shown in Table 1.

On the contrary, the results revealed that the lowest mean of leakage $(3.2175 \mathrm{~mm})$ was recorded in group 1 (with smear layer) and the highest mean of leakage $(6.8750 \mathrm{~mm}$ ) was recorded in group 2 (without smear layer). The extent of dye penetration in millimeters, the means, and the standard deviations for each group are listed in Table 2.

In the positive control group the three roots showed dye penetration over the entire length of the root canal, whereas all three roots in the negative control group showed no evidence of dye penetration which proves that the conditions of the tests are correct.

Data for apical leakage which subjected to MannWhitney U-test revealed that there were statistically significant differences among the groups (0.05).

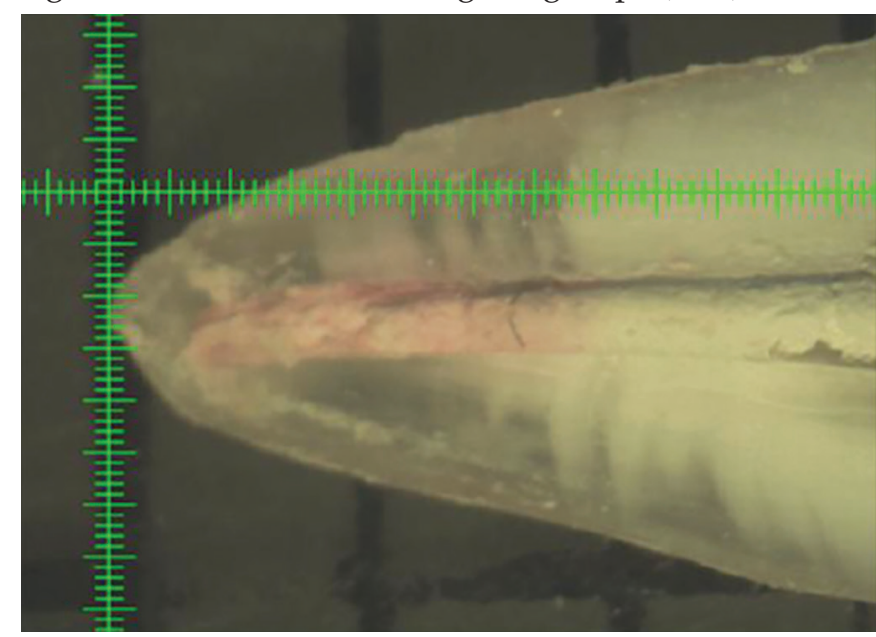

Fig. 2: A stereomicroscope image $(x 20)$ of the sample from group 2 (medium infiltration) 
Usage of Mineral Trioxide Aggregate as Obturation Material

Table 1: Scores for apical dye penetration evaluation by

Escobar et al criteria

\begin{tabular}{llll}
\hline Groups & Score & & \\
\hline & 0 & 1 & 2 \\
\hline 1 & 6 & 5 & 9 \\
2 & 0 & 3 & 17 \\
\hline (0. Best; 2. Worst) & &
\end{tabular}

When the smear layer was present, MTA revealed less leakage compared to the group of MTA without smear layer with statistically significant difference $(p<0.05)$.

\section{DISCUSSION}

One of the main reasons of endodontic failure is the leakage, both apically and coronally, into and out of the canal space. ${ }^{18}$ There are several test methods used to evaluate the sealing quality produced by root canal obturation materials. The most famous method used is dye penetration because it is easy to handle and does not need complicated materials. ${ }^{19}$

Methylene blue is commonly used in marginal sealing studies, but its incompatibility with alkaline substances may cause discoloration of the dye. ${ }^{20}$ Calcium hydroxide results from mixing calcium oxide, which is found in MTA, with water leading to a subsequent increase in $\mathrm{pH} .{ }^{21}$ Thus, discoloration of the surfaces stained by methylene blue may occur. Therefore, using rhodamine B dye solution for assessing the sealing ability of MTA is more suitable. 22,23

When smear layer was removed, root canals were irrigated with $1 \mathrm{ml}$ of daily prepared $5.25 \% \mathrm{NaOCl}$ after each instrument using Max-I-Probe irrigation probes size 30 gauge and final irrigation with $3 \mathrm{ml}$ of $17 \%$ EDTA for 1 minute followed by $3 \mathrm{~mL}$ of $5.25 \% \mathrm{NaOCl}$. It was observed that $17 \%$ of EDTA has the potential for causing excessive peritubular and intertubular dentinal erosion if the application time exceeds $1 \mathrm{~min}$. Thus in the present study, EDTA had application time which was limited to 1 minute. $^{24}$

It is known that EDTA alone does not completely remove the smear layer, ${ }^{25}$ and that the best results are achieved with EDTA combined with sodium hypochlorite solutions. ${ }^{15,26,27}$ Because using solutions such as EDTA and sodium hypochlorite leaves crystals on the canal walls, and it could be beneficial to make a final irrigation step with $5 \mathrm{~mL}$ distilled water. ${ }^{28}$

The result of our study indicated that using MTA as a root canal filling material in free smear layer root canals causes more apical leakage than using MTA in positive smear layer root canals with statistically significant differences between the two groups $(p=0.003)$. It could be assumed that smear layer plays the role of a coupling agent that improves the bonding between MTA and the tubular dentin, and the fact that MTA is a hydrophilic
Table 2: Extent of apical dye penetration ( $\mathrm{mm}$ )

\begin{tabular}{llllll}
\hline Group & $n$ & $\begin{array}{l}\text { Minimum } \\
(\mathrm{mm})\end{array}$ & $\begin{array}{l}\text { Maximum } \\
(\mathrm{mm})\end{array}$ & $\begin{array}{l}\text { Mean } \\
(\mathrm{mm})\end{array}$ & $\mathrm{SD}$ \\
\hline 1 & 20 & 0.00 & 10.00 & 3.2175 & \pm 2.66119 \\
2 & 20 & 2.00 & 16.00 & 6.8750 & \pm 4.15133 \\
\hline
\end{tabular}

material and sets in the presence of moisture could have a positive effect to improve the adaption between MTA and the walls of the root canal. This finding is supported by the studies of Yildirim et al., ${ }^{29}$ Yildirim et al., ${ }^{30}$ and de Souza et al., ${ }^{31}$ but is not in agreement with the study conduct by Li and Zhang which demonstrated that removal of the smear layer did not cause significantly less apical leakage than that when the smear layer was left intact. ${ }^{32}$

The previous finding indicated that leakage significantly increases when using sodium hypochlorite with a mixture of tetracycline, an acid, and a detergent (MTAD) or EDTA before placing WMTA for perforation repair in comparison to using only $\mathrm{NaOCl}$ or no irrigation. ${ }^{33}$ Another study revealed that WMTA partially dissolves when it remains in contact with BioPure MTAD for 5 minutes. ${ }^{34}$

The use of MTA as an obturating material was clinically supported, in some case reports. ${ }^{3}$ Complete or partial obturation of the root canal system by using MTA is a viable option for teeth that exhibit extensive internal root resorption, ${ }^{35}$ open apices, and selected cases that show anatomic variations that include dens evaginatus, C shaped canals, fusion, or gemination. ${ }^{3}$ On the other hand, some studies revealed the capacity of MTA to reinforce the immature teeth and increase their fracture resistance. ${ }^{36,37}$

\section{CONCLUSION}

In conclusion, under the conditions of this in vitro study, the apical seal produced by MTA when the smear layer is left intact was better than the apical seal of MTA when the smear layer is removed.

It can be stated that MTA is a promising root canal filling material with good sealing ability in the presence of a smear layer.

\section{Clinical Significance}

Using white MTA material for obturation of root canals is a useful procedure. It can be done without complexity in irrigation during root canal treatment and cause no discoloration to the teeth.

\section{Limitation of the Study}

The present study has some limitations that should be considered. This in vitro study was carried out on 
extracted teeth. However, laboratory conditions are not exactly similar to that of clinical conditions, and results obtained by in vivo studies may differ. In addition, there are no other studies for evaluation of the apical seal of MTA in the absence and presence of smear layer.

\section{ACKNOWLEDGMENT}

Authors acknowledge staff of faculty of dentistry in Aleppo university/Syria, and the staff of Faculty of Pharmacy and Dentistry, Buraydah Colleges, Al Qassim, Saudi Arabia, and the staff of dental college in Alfarabi colleges (Riyadh/KSA).

\section{REFERENCES}

1. Wu MK, De Gee AJ, Wesselink PR. Leakage of AH26 and Ketac-Endo used with injected warm gutta-percha. J Endod 1997 May;23(5):331-334.

2. Gartner AH, Dorn SO. Advances in endodontic surgery. Dent Clin North Am 1992 Apr;36(2):357-378.

3. Bogen G, Kuttler S. Mineral Trioxide Aggregate Obturation: A review and case series.J Endod 2009 Jun;35(6):777-90.

4. Lee SJ1, Monsef M, Torabinejad M. Sealing ability of a mineral trioxide aggregate for repair of lateral root perforations. J Endod 1993Nov;19(11):541-544.

5. Torabinejad M, Hong CU, McDonald F, et al. Physical and chemical properties of a new root-end filling material. J Endod 1995Jul;21(7):349-353.

6. Parirokh M1, Torabinejad M. Mineral trioxide aggregate: a comprehensive literature review-Part I: chemical, physical, and antibacterial properties. J Endod 2010Jan;36(1):16-27.

7. Asgary S, Parirokh M, Egbbal MJ, et al. Chemical differences between white and gray mineral trioxide aggregate. J Endod $2005 \mathrm{Feb} ; 31(2): 101-103$.

8. Torabinejad M, Chivian N. Clinical applications of mineral trioxide aggregate. Review. J Endod 1999 Mar;25(3):197-205.

9. Gomes-Filho JE, Watanabe S, Bernabé PF, de Moraes Costa MT. A mineral trioxide aggregate sealer stimulated mineralization. J Endod 2009 Feb;35(2):256-260.

10. Holland R, Mazuqueli L, de Souza V, et al. Influence of the type of vehicle and limit of obturation on apical and periapical tissue response in dogs' teeth after root canal filling with mineral trioxide aggregate. J Endod 2007 Jun;33(6):693-697.

11. Lim TS, Wee TY, Choi, et al. Light and scanning electron microscopic evaluation of glyde file prep in smear layer removal. Int Endod J 2003 May;36(5):336-343.

12. Jeon IS, Spänberg LSW, Yoon TC, et al. Smear layer production by 3 rotary reamers with different cutting blade design in straight root canals: a scanning electron microscopic study. Oral Surg Oral Med Oral Pathol Oral Radiol Endod 2003 Nov;96(5):601-607.

13. Hülsmann $M$, Schade $M$, Schäfers F. A comparative study of root canal preparation with Hero 642 and Quantec SC rotary NiTi instruments. Int Endod J 2001 Oct;34(7):538-546.

14. Sen BH1, Wesselink PR, Türkün M. The smear layer: a phenomenon in root canal therapy. Int Endod J 1995 May;28(3):141-148.

15. Yamada RS, Armas A, Goldman M, et al. A scanning electron microscopic comparison of a high volume final flush with several irrigating solutions: Part 3. J Endod 1983 Apr; 9(4):137-142.
16. Putzer P, Hoy L, Günay H. Highly concentrated EDTA gel improves cleaning efficiency of root canal preparation in vitro. Clin Oral Investig 2008 Dec;12(4):319-324.

17. Escobar C, Michanowicz AE, Czonstkowsky M, et al. A comparative study between injectable low-temperature $\left(70^{\circ} \mathrm{C}\right)$ gutta-percha and silver amalgam as a retroseal. Oral Surg Oral Med Oral Pathol Oral Radiol Endod 1986 May;61(5):504507.

18. Lamb EL, Loushine RJ, Weller RN, et al. Effect of root resection on the apical sealing ability of mineral trioxide aggregate. Oral Surg Oral Med Oral Pathol Oral Radiol Endod 2003 Jun;95(6):732-735.

19. Bodrumlu E, Tunga U. Apical leakage of Resilon obturation material. J Contemp Dent Pract 2006 Sep 1;7(4):45-52.

20. Coneglian PZ, Orosco FA, Bramante CM, et al. In vitro sealing ability of white and gray mineral trioxide aggregate (MTA) and white Portland cement used as apical plugs. J Appl Oral Sci 2007Jun;15(3):181-185.

21. Duarte MA, Demarchi AC, Yamashita JC, et al. PH and calcium ion release of 2 root-end filling materials. Oral Surg Oral Med Oral Pathol Oral Radiol Endod 2003 Mar;95(3):345347.

22. Moraes IG, Moraes FG, Mori GG, et al. Influence of calcium hydroxide on dyes for dentin labeling, anlyzed by means of a new methodology. J Appl Oral Sci 2005 July/Sept;13(3):218221.

23. Tanomaru-Filho M, Figueiredo FA, Tanomaru JMG. Effect of different dye solutions on the evaluation of the sealing ability of mineral trioxide aggregate. Braz Oral Res 2005;Apr/June 19(2):119-122.

24. Calt S, Serper A. Time-dependent effects of EDTA on dentin structures. J Endod 2002 Jan;28(1):17-19.

25. Baumgartner JC, Mader CL. A scanning electron microscopic evaluation of four root canal irrigation regimens. J Endod 1987 Apr;13(4):147-57.

26. Lottanti S, Gautschi H, Sener B, et al. Effects of ethylenediaminetetraacetic, etidronic and peracetic acid irrigation on human root dentine and the smear layer. Int Endod J 2009 Apr;42(4):335-343.

27. Paul ML, Mazumdar D, Niyogi A, et al. Comparative evaluation of the efficacy of different irrigants including MTAD under SEM. J Conserv Dent 2013 Jul-Aug; 16(4): 336-341.

28. Dotto SR, Travassos RMC, de Oliveira EPM, et al. Evaluation of ethylenediaminetetraacetic acid (EDTA) solution and gel for smear layer removal. Aust Endod J 2007 Aug; 33(2):62-65.

29. Yildirim T, Oruçoğlu H, Cobankara FK. Long-term evaluation of the influence of smear layer on the apical sealing ability of MTA. J Endod 2008;34:1537-1540.

30. Yildirim T, Er K, Taşdemir T, et al. Effect of smear layer and root-end cavity thickness on apical sealing ability of MTA as a root-end filling material: a bacterial leakage study. Oral Surg Oral Med Oral Pathol Oral Radiol Endod 2010 Jan;109(1):e67e72.

31. de Souza AB, de Amorim C, Marques J. Effect of diode laser irradiation on the apical sealing of MTA retrofillings.Braz Oral Res 2006 Jul-Sept; 20(3):231-234.

32. Li S, Zhang $Q$. Effect of smear layer on apical sealing ability of mineral trioxide aggregate (MTA) Plus through the sucrose penetration mode. Beijing Da Xue Xue Bao Yi Xue Ban 2018 Jun 18;50(3):560-563.

33. Uyanik MO, Nagas E, Sahin C, et al. Effects of different irrigation regimens on the sealing properties of repaired furcal 
perforations. Oral Surg Oral Med Oral Pathol Oral Radiol Endod 2009 Mar;107(3):e91-e95.

34. Smith JB, Loushine RJ, Weller RN, et al. Metrologic evaluation of the surface of white MTA after the use of two endodontic irrigants. J Endod 2007 Apr;33(4):463-67.

35. Jacobovitz M1, de Lima RK. Treatment of inflammatory internal root resorption with mineral trioxide aggregate: a case report. Int Endod J 2008 Oct;41(10):905-912.
36. Bortoluzzi EA, Souza EM, Reis JM, et al. Fracture strength of bovine incisors after intra-radicular treatment with MTA in an experimental immature tooth model. Int Endod J 2007 Sep;40(9):684-691.

37. Milani AS, Rahimi S, Borna Z, et al. Fracture resistance of immature teeth filled with mineral trioxide aggregate or calcium-enriched mixture cement: An ex vivo study. Dent Res J 2012 May-Jun;9(3): 299-304. 